\title{
SEMANTIC REPRESENTATION AND THE TRANSLATION OF POETRY
}

\author{
Judith A. Campbell \\ Graduate School for Translators and Interpreters \\ University of the Witwatersrand
}

\begin{abstract}
Acknowledged as the most difficult of all types of translation the translation of poetry has provided a focal point for attempts to create a theory of translation. Until recently the focus has been on the comparison and evaluation of originals and their translations, leaving the actual process of the translation of poetry largely neglected. The reasons for this are clear: it is extremely difficult to describe objectively a process that has been universally accepted as inherently creative. It is also problematic to obtain reliable information from subjects under test conditions. ${ }^{1}$ How might the science of linguistics solve the dilemma faced by translation theorists and linguists when attempting to construct a model of translation theory which will encompass "poetic" texts?
\end{abstract}

It has proved extremely difficult to construct anything resembling a theory of translation as such, although various "theories" have been proposed. ${ }^{2}$ Many linguists have ignored the field of translation studies, which has largely been dominated in recent years by literary specialists, while many translation theorists have neglected to take into account recent advances in modern linguistics. ${ }^{3}$ Bell suggests that it is now possible to construct an adequate theory of translation, ${ }^{4}$ or at least a theoretical approach to the translation process, making use of current advances in cognitive science, artificial intelligence and text linguistics, basing such an approach on a broadly functional theory of language. ${ }^{5}$ The question still remains however, whether it is possible that such a model would also be able to deal with the specific problems posed by poetic texts.

Within the framework of Bell's model the translator processes the text according to three areas of operation. Firstly, the text is broken down clause by clause to provide information on its syntactic structure. The text then enters a stage of semantic analysis, where the task of "concept recovery" is undertaken. The next stage consists of a pragmatic analysis in which the communicative function of the text is determined. A "semantic representation" of the text is thus created in the mind of the reader, clause by clause. ${ }^{6}$ This representation 
passes through a complex reverse process of synthesis in order to produce the translated text. During this stage of the process the translator is obliged to make numerous decisions about how to deal with the purpose, thematic structure, and style of the original. It should be emphasised that the whole process of analysis and synthesis is not of course a linear process, but is an example of top-down/bottom-up processing.

The pragmatic analysis takes into account the tenor of the discourse, or the relationship with the receiver of the text, the mode of discourse, or the medium of the text, and the domain of the discourse, or the role played by the text in a communicative activity. ${ }^{7}$ The latter category also determines the function of the text, whether it is referential, emotive, conative, phatic, or poetic. It is this section of the analysis which might be expanded to include an analysis of those features of relevance to the translation of poetry. In such texts the function of the text would be described as "poetic" or also "emotive", or perhaps an "aesthetic function" might be added here.

Bell applies his model to the analysis of a short poem, but fails to take into account the overall semantic representation of the poem, despite the fact that his model makes use of this concept. He concentrates instead on a clause by clause analysis. He opts out of the most serious problems involved in applying his model to the process of the translation of poetry, ending his discussion with the synthesised translation at a stage that he describes as "a translation that a computer programme might have produced". He states that the next stage involves stylistic decisions which "depend on personal taste". 8 A model dealing with the translation of poetry must be able to deal with these decisions and the process leading to them. It is these decisions that determine whether or not the translation becomes a poem in the target language.

De Beaugrande's model, in contrast, focuses on the textual aspects of poems and their translations, building up textual worlds which are modelled as "configurations of concepts". 9 Although his model is at times bafflingly detailed, there is no indication of whether the diagrammatic representation of the poem's textual world - which is compared with diagrammatic representations of the textual worlds of the translations - is meant to coincide with the semantic representation of the poem in the mind of the reader, or whether this textual world is a fixed and objective configuration. Certainly the implication is rather the latter case, which does not however remove the possibility for infinite interpretation present in any literary text - indeed it is claimed that it ensures such infinite interpretation. 
A notable gap in his model is left by a failure to include any consideration of the sound texture of the poems analysed - other than in a discussion of the central nature of rhyming concepts - as he concentrates exclusively on syntactic and semantic categories in terms of strategies for textual equivalence. Nor does he enter into any detailed discussion of the "meaning" of individual words nor of the "semantic representation" produced in the mind of the reader or processor of the text.

The most useful concept in de Beaugrande's work is his distinction between a readeroriented translation, in which the translator is aware that his response is only one among many, and a translator-oriented translation, where the translator substitutes his own interpretation for the entire meaning potential that the text may have. If one compares several translations of the same poem it is usually obvious that the range of meanings available in the original inevitably changes in the translation. This phenomenon has been described as the appropriation of an original text by the translator. This is particularly evident when the translator is himself a poet, for example Pope's translations of Homer and Bal'mont's translations of Shelley which are so influenced by the translator's own style that Chukovsky refers to the "Bal'montisation" of Shelley culminating in the epigraph 'Shellmont'. ${ }^{10}$ In a reader-oriented translation - which is proposed as the more desirable type of translation - a translator will endeavour to preserve the polyvalent quality of the poem as in the original. ${ }^{11}$

In poetry the meaning of a word, because of the density of significance, is largely influenced by the paradigmatic and syntagmatic associations existing in the mind of the reader. This type of analysis of meaning can be dealt with by means of a semantic or lexical field, where words are linked to each other in terms of collocation and association as well as by phonological characteristics. In addition, as the boundary between denotational and connotational meaning is fuzzy rather than fixed, certain concepts formulated in prototype semantics may be applied. Each concept or word may be regarded as having an encyclopaedic entry in the memory which contains all relevant features. Bell suggests three parameters: class, characteristic, and example. A concept therefore belongs to a class of concepts, possesses certain defining properties as well as further qualities, and also supplies examples of itself based on previous experience. Such a storage facility in the long-term memory enables links and cross-links to be established between entries. ${ }^{12}$ 
One of the characteristics of poetic language is its unexpectedness for the reader. ${ }^{13}$ The reader attempts to make sense of the text by looking for equivalences and oppositions from the context as well as the co-text. The world-knowledge of the reader/translator must therefore include the ability to understand and perceive the multiple meanings available in the text as well as the ability to restructure these meanings in a poetic text in the target language - hence the reference to decoding and encoding skills. It is thus important to examine both the process of interpretation by the translator-reader, and the process of "recreation" by the translator-poet.

The associations activated by the elements of the poem, together with all other aspects of meaning will differ from reader to reader, as no one person's knowledge of the world is identical to another's. Each person involved with the text - the original author, the translator-reader, the translator-producer, and the receiver audience in the target language - plays some part in the life of the text and brings a different background to it. Nevertheless, while the possibilities for actualising the meaning of the text may be infinite and change along with readers' horizons, the meaning potential of the text does remain constant, in the sense that the text itself is fixed. It may be this that suggests that an objective analysis and a model for that analysis is feasible.

In order to provide a more comprehensive model (although no definitive solutions are offered here) I would like to propose the application and modification of Fillmore's theory of scenes-and-frames semantics. ${ }^{14}$ Fillmore adopts the idea of a frame from cognitive psychology, in which field several different terms have been used for similar concepts. For example, Minsky introduced the term "frames" for stereotyped situations, subsequently extended to linguistic "facts". ${ }^{15}$ The term "script" was applied to a conceptual dependency network which would represent the meanings of sentences in conceptual terms. Other terms which have been used include "scenarios" and "schemata": the former are situationspecific while the latter represent more general types of knowledge structure, and may vary considerably with different cultural backgrounds. ${ }^{16}$ Thus personal histories and interests may contribute to the creation of higher level schemata which cause messages to be understood in certain ways. This idea can be taken further, so that schemata represent stereotypes of concepts or prototypical instances of concepts. ${ }^{17}$.

In Fillmore's terms the frame can be described as a "linguistic coding" which refers to the encoding of any real-life situation and which may be associated with prototypical instances of scenes. ${ }^{18}$ The term "scene" refers to any kind of standard scenario, institutional 
structure, body image, and "any kind of coherent segment..... of human beliefs, actions, experiences, or imaginings. ${ }^{19}$ Scenes and frames constantly activate each other and evoke further associations, so that every linguistic expression in a text is conditioned by another one. This concept may account for the dynamic aspect of reading and assimilating a text, and hence for the construction of a semantic representation of the text in the mind of the reader. It can also explain why the same text may be interpreted in many different ways, exemplifying the polyvalent potential of a text.

It was noted above that in poetry considerable use is made of syntactic and semantic deviation. It is this unexpected use of language that we have said largely distinguishes a poetic text from a prose text. The "unexpectedness" of a word or of the combination of structure and meaning focuses the reader's attention by its very unpredictability. A reader will endeavour to establish links and to "make sense" of such links even when the language used is "unusual" in this way. Indeed an extension of the more general concept of the existence of "mental models" suggests that it is not entirely satisfactory to subscribe to an approach to meaning which depends on the decomposition of word meaning in order to understand the meaning of sentences. A classic example is that we all understand the sentence:

The book fills a much-needed gap.

although the word-meaning makes little sense. Thus we use words in a sentence "as cues to build a familiar mental model". ${ }^{20}$ Understanding takes place through the construction of such mental models, which are continually modified and even abandoned as the text continues. The process of interpretation can thus be seen as cyclical. These mental models can be seen to be constructed by mearis of the activation of frames and scenes in the mind of the reader.

The concept of scenes and frames also allows for the activation of further scenes related to a reader's previous experience of poetic texts. It is in this way that a reader may recognise a text as belonging to a specific text type. Within the field of poetic texts individual genres of poetry may be recognised as "prototypical", that is, a particular poem may activate a "sonnet" scene, or a "lyric" scene. This idea is crucial in translating across boundaries of differing cultural and literary traditions. There may be a "gap" in the structure of individual knowledge bases making up the general background knowledge of the reader. Alternatively, if for example the metric scheme in the target language fulfils a different function from that of the same metric scheme in the source language then an "inappropriate" scene will be activated. The reader will always search for a scene which 
provides the closest "fit"." If however there is no scene which fits, then it may be possible to fill the gap with a new concept eventually leading to the establishment of additional links in the network and the construction of further scenes.

If we now take an example of a poem and translations of that poem we can address the question of how the different scenes and frames activated by a potential target text reader compare with those activated by a potential source text reader? What does this imply for the translator of the poem and what do different translations reveal about the analytical process adopted by the transiator? It should be emphasised that the concept of scenes and frames used here is not restricted to stereotypical situations. I am adapting the concept in order to deal with the activation of culturally linked scenes as well as with scenes associated with the use of certain words and sounds or the combinations of those words and sounds in a poetic text.

The poem to be discussed is by Osip Mandel'shtam, a leading twentieth century Russian poet, who was himself an accomplished translator of poetry. The poem shows plainly the transition from a predominantly Symbolist and even Romantic phase in Mandel'shtam's poetry, to a more definite Acmeist phase. The Acmeists considered precise language and clarity to be of the utmost importance, and their poetry was always firmly related to an objective reality. ${ }^{21}$ It is essential that any theory concerning the translation of poetry should take into account the attitude of the original poet to the material of his trade. Thus before beginning on a translation the translator should familiarise himself with the theoretical and prose works of the poet he is to attempt to translate. This would need to be added to the initial stage of the analysis and would constitute part of the prior knowledge of the translator, alongside his source and target language knowledge, text-type knowledge and domain knowledge. 22

The poem has as its central theme the endurance of the artistic form, and also illustrates the Acmeist cult of the precise:
Na bledno-goluboy emali, Kakaya myslima v aprele, Berezy vervi podnimali I nezametno vechereli.
Uzor ottochenny i melkiy, Zastyla tonen'kaya setka, Kak na farforovoy tarelke Risunok, vycherchenny metko, 
Kogda ego khudozhnik mily
Vyvodit na steklyannoy werdi,
B soznanii minutnoy sily,
V zabvenii pechal'noy smerti. ${ }^{23}$

This is one of Mandel'shtam's most haunting and evocative poems, describing the artist's moment of creation. Indeed, Clarence Brown goes so far as to say that Mandel'shtam never exceeded the "sheer verbal beauty" of this lyric. ${ }^{24}$. In order to perform an analysis of the original poem, a linear approach will have to be adopted, although all aspects and features of poetry combine to produce the overall semantic representation in the mind of the reader.

Rhyme and the sound of words are of supreme importance in Mandel'shtam's poetry. Indeed, he is one of the very few poets who composed in his head before committing his verse to paper:

Mandel'shtam seldom prepared rough drafts of his poems on paper: he composed them "on the lips", modelling sometimes for weeks on end phonctic elements and layers of meaning into a coherent whole. ${ }^{25}$

In this poem, the metre is regular within each stanza while the rhyme scheme also follows a fixed pattern. In Russian this is the norm for Symbolist and Acmeist poetry, and it thus serves to locate the poetry in a particular tradition and genre. More generally Russian poetry of the twentieth century makes much more use of rhyme and traditional metre than its English counterpart. This is a good example of the association of a quite different scene in terms of literary tradition with the frame of rhyme and regular metre.

The focus first is on the translator as reader. The poem is read, and a "semantic representation" is created swiftly in the mind of the reader. This representation is not necessarily static however. As the poem is read and reread it will shift and change substantially. The scenes and frames activated on the first reading will in turn activate further scenes and frames and hence further semantic associations during the second and subsequent readings.

The main image is introduced immediately. The idea of "pale-blue enamel" evokes a scene relating to chinaware and crockery. Yet in the very next line the association with April 
forces the reader to reassess his initial interpretation and relocate the meaning in a further scene which can incorporate an association with April. Here we encounter a basic cultural conflict - in a Northern European Russian context, April will trigger a "spring" scene, while in the southern hemisphere the association will involve autumn. As it happens, in both hemispheres April may mean crisp blue skies, which is the frame relevant here. The third line introduces a further northern hemisphere, and now specifically Russian scene - birchtrees. These are the most commonly found trees in large areas of Russia, and thus serve a different function in the source language than in the target language, where birch trees signify a Russian, and therefore foreign, landscape.

In the final line of the first stanza the poet makes use of deliberately "incorrect" syntax, jolting his readers into an awareness of the language and making absolutely certain that the reader is now aware that this is a poetic text. The use of the verb "vecheret" is normally impersonal and intransitive, meaning "drawing towards evening" and would normally be translated by "evening is drawing in" or "dusk is falling". One would expect the form "vecherelo" in the past tense - the neuter impersonal form of the verb. The rhyme however demands "vechereli" in the plural, making the birch trees themselves the subject. For the Russian reader it is clear that the poet is using this verb in a figurative sense, and the darkness is now seen to be caused by the shadow of the tall branches of the trees, the verb thus assigning an active role to these branches. For the translator/reader this presents a seemingly insoluble problem.

The translation by James Greene which appears below uses the word "hammocks" and Clarence Brown's translation includes the line: "and vespered imperceptibly". Both have perceived the unusual use of language and attempted to compensate by using English in a similarly unusual manner. Unfortunately the words chosen in both of these translations activate quite different scenes: "hammocks" evokes a very specific scene of sleeping, ships and even sailors with all the associations of those scenes, while "vespered" introduces a religious scene, which is totally absent in the source text. In a translation that does not seek to capture this unusual use of language, Robert Tracy simply says: "And shyly it was evening", thus deliberately omitting a scene of considerable importance in the source text, perhaps because a satisfactory solution eluded him.

In the next stanza Mandel'shtam moves from a picture of nature to an image of a human craft - the design on porcelain- and then to the identification of the two images in the last stanza. The poem concretises the image of the branches against the sky in an image of a 
finely etched pattern on porcelain by a process of 'metonymy. At the end of the stanza the reader has been brought full circle, back to the image of the pale-blue enamel in the first line. The vocabulary in this stanza is delicate, creating an overall image of finely drawn patterns using delicate strokes on fragile porcelain. It should be emphasised that in terms of the framework used here, the words combine to produce the "scene" and that it is impossible to isolate the meaning of one word from the meaning of the words in close proximity to it.

The final stanza carries through syntactically from the second, but now links the concretisation of the image with the creative act of the artist. The poem now focuses on the transitory nature of the act of artistic creation and the mortality of the artist himself contrasted with the permanence of the created work. The poet emphasises, with the use of the word "tverdi", the hardness and concreteness of the plate, and hence its durability, in contrast with the vulnerability and mortality of the poet.

By the end of the first reading of the poem the reader has moved backwards and forwards, accessing further scenes as other linguistic and poetic frames are brought into play by the poet. As unexpected scenes are activated so the reader searches for associations that will enable him to process and interpret the poem in a manner satisfactory for him. The amount of effort put into this act of interpretation will be linked primarily to the extent of the reward the reader expects to get from an interpretation of the poem. This will govern the extent to which the various potential meanings of the poem are available to the reader/translator, and hence the extent to which these may be reproduced in the target language text.

It will be clear that it is not possible to concentrate only on the denotative and connotative meaning of the poem on a lexical level. The rhyme and the metre interact with the meaning in giving form to the scenes activated by the poem. The emphasis on the precise pattern of the branches against the sky and the lines etched on the porcelain is reinforced by the shape of the rhyme - including internal rhyme - and the metre. In the first stanza the sound [l] is used in each line as part of the rhyme, as well as earlier in the first and second lines. In the Russian phonological system there is both a soft - that is, palatalised, [1], and a hard [1], depending on the consonant which follows. Both of these are exploited in the first stanza, contributing to the gentle fluidity of the content of the poem. In the second stanza the rhyme focuses on the [ $k$ ] sound, which is similarly repeated earlier in the second, third and fourth line. Again use is made of both hard and soft consonants, while 
the final syllable of each line is unstressed, therefore masking the quality of the vowels. In the last stanza the rhymes consist of [d] and [t], alternating with [l]. The last stanza thus departs slightly from the rigidity of the first two stanzas. The sequence of sounds and the constancy of the metre - three stressed syllables in each line - add to the overall impression created in the mind of the reader, giving the poem an elusive melodic quality, full of soft, fluid sounds and evocative of a finely crafted image.

The best overall translation in terms of a purely subjective opinion is one that departs quite radically from the original in terms of syntax and form and yet which best seems to capture the "essence" of the original poem. I am aware that here I am using a subjective notion of "best", that is, as perceived by myself. Here is a translation of the poem, by James Greene:

\author{
April-blue enamel: \\ Pale \\ And inconspicuous. \\ A birch-tree hammocks in the evening sky. \\ Fine netting cuts \\ Thin patterns perfectly: \\ Designs on porcelain plates \\ Traced keenly \\ By courteous \\ Artist on a fimament of glass, \\ Knowing his short-lived strength, \\ Unconscious of sad death.. \\ (Translated by James Greene) ${ }^{26}$
}

Here the image of April is the very first image in the poem, and hence the first scene to be activated. This changes the sequence of interpretation and hence the associations evoked. The first stanza is altered considerably. Here the birch tree is the hammock, and the link is more obscure than in the original poem so that the reader of the translation is obliged to work harder to fill in the gaps and to make sense of what he is reading. In the second stanza the first line of the translation makes use of an active verb, "cuts", thus evoking a scene involving a knife, and the active use of that knife. Again in the last two lines of the stanza instead of making use of a metonymic image, as in the original text, the patterns are now cut directly onto the plates - plural, and not singular as in the original. Several quite different scenes have now been activated by means of the use of frames which do not correspond to those present in the original text. Only in the last stanza does the translator return to the metaphor of the original, and even here the metaphor is more explicit, 
referring to the "firmament" instead of the "hardhess". The use of the word "firmament" introduces an additional scene, relating to the heavens and linking up with the sky in the first stanza, which is in fact never mentioned explicitly in the original.

An alternative translation, which seeks to retain the regular rhyme scheme and metre of the original, is by Robert Tracy:

\author{
Against pale blue enamel, the shade \\ That only April can bring. \\ The birch tree's branches swayed \\ And shyly it was evening. \\ The pattern, precise and complete, \\ A network of thinly etched lines \\ Like the ones on a porcelain plate \\ With its carefully drawn design, \\ When the dear artist creates \\ The design on the glaze's hardness, \\ At that moment his skill awake, \\ No thought for death's sadness. ${ }^{27}$
}

Here the constraints imposed upon the translator by his determination to retain the rhyme scheme have a catastrophic effect. Firstly the translator does not succeed in producing a poem which corresponds in any way to the original other than in the sense of a restricted conceptual meaning. The rhymes are banal and contrived and result in a quite drastic change in the meaning of the poem. In direct contrast to the scene created by the pale-blue enamel, the word "shade" evokes a far more wintry scene. Using the word "shyly" in the last line of the first stanza personifies an indeterminate concept in the poem, as the birch trees are personified in the original, but the two have very different connotations. The overall representation is far more pedestrian and laboured, the translator loses the ease with which the original seems to have been composed. A reading of this translation immediately after a reading of the version by James Greene will leave the reader with a very different semantic representation. This could perhaps be tested empirically if a large enough sample were used, and the method of describing the representation were clearly defined.

I have attempted to illustrate that the ideological and aesthetic commitment brought to the text by both author and reader and hence by both reader and translator governs the way in which the overall meaning potential of the text is actualised. The way in which a reader 
constructs a representation of the text and relates this to the real world seems to be the very core of the problems associated with the translation of poetry. This "knowledge-ofthe-world" aspect of reading a text has been most extensively discussed in texts on discourse analysis. In artificial intelligence this stored information or data bank is likened to an "expert" system in computing. In computing it proved impossible to store all such knowledge in one data base different storage areas were therefore created for different "worlds" or interlinked knowledge areas. Thus when reading a text we select and access only that storage area which is of relevance to the subject of the text. In poetry however for a successful reading and a rewarding interpretation of the text more storage areas need to remain open and to be accessed while reading.

In the translation of poetry the goal is to convey not only the "meaning" of the text but also the ways in which the concrete word and fabric of language is used to communicate that meaning and to supplement it. Perhaps we are in fact embarking on a discussion of how a poet/translator processes the world, and hence the way he processes the original poem before he attempts to recreate a new one. A model which succeeds in describing the process of the translation of poetry would provide us with considerable insights into the techniques used for decoding and re-encoding a text with the aim of producing an equivalent effect on the target language and source language audience. The problem is that there is no such thing as a quantifiable effect which can be quantified and therefore reproduced. Each reading of the poem will differ, so that it may well be impossible to retain the total polyvalent quality of the meaning potential of a poem.

It becomes increasingly difficult to envisage a model of the translation process that will be able to take into account the issue of personal taste and individual appreciation of literature. It was my intention to illustrate that this could be done, and that a structured model could indeed be created, with the help of certain insights from modern linguistics. It may be that further developments in cognitive linguistics and in artificial intelligence will have to be awaited in order to construct such a model. Alternatively we may have to abandon the idea of a full working model of a general overall theory of translation and confine ourselves to the construction of theories in a piecemeal fashion, linked to a theory of text typologies. In the end, it seems that a translator of poetry is obliged to make use of numerous skills, and in the choices exercised, whether equivalent to the devices, strategies and words used in the source text or not, lies his creative freedom, which can be described objectively no more than the genius of poets such as Pushkin. Goethe, or Shakespeare. 


\section{FOOTNOTES}

1. Francis Jones, in a recent article, suggests that the only reliable sources of data on the process of poetic translation are the poet/translators themselves, and their comments on the processes and procedures that they use and experience - Jones, F. 1989, p184.

2. Proffered theories or more accurately, descriptions of the translation process include Kuic 1970, Delisle, 1980, Bly 1984, Weaver 1989, Jones 1989, and Raffel 1988.

3. With the exception of writers such as Nida 1964,1960,1974, Catford 1965, Wilss 1980 , 1982, and possibly Lefevere 1975.

4 Bell, 1991, p xvi.

5. See for example Halliday, M. 1985.

6 Bell, 1991, pp46-59.

7. Bell, 1991 p54.

8. Bell, 1991, p75.

9. de Beaugrande, 1980, p30ff.

10. Chukovsky, p26.

11. de Beaugrande, $1980, \mathrm{p} 26$.

12. Bell 1991, pp245-8.

13. de Beaugrande, $1980, \mathrm{p} 23$.

14. This theory was first mentioned with reference to translation by Snell-Hornby 1988 , pp79-86. Fillmore's own discussion can be found in various sources, including Fillmore, C. 1977, Scenes and Frames Semantics, in Dirven and Radden, (eds).

15. For a fuller discussion of these terms see Brown and Yule, 1983, pp238-254.

16. See Sanford and Garrod 1981.

17. Brown and Yule, 1983, p249.

18. Fillmore, C. $1977, \mathrm{p} 82$.

19. Snell Hornby 1988, p79.

20. Brown and Yule, 1983, p251.

21. Tracy, R. 1981, p21.

22. These are areas of knowledge indicated by Bell, and discussed above.

23 A "literal" prose rendering of the poem would be as follows: On the pale-blue enamel/Which is conceivable in April/The birch trees' branches lifted up/And imperceptibly grew dusk. The finished and fine pattern/the thin net hardens/As on a porcelain plate/The design, finely drawn, / When its dear artist/Traces on the glazed hardness/Conscious of the passing strength,/Oblivious of sad death.

24. Brown, C. 1973, p168.

25. McDuff, D. 1973, pxix.

26. Greene, 1980.

27. Tracy, R. 1981, p55. 


\section{BIBLIOGRAPHY}

de Beaugrande, R. 1980. "Towards a semiotic theory of poetic translating" in Wilss, W. (ed.) 1980. 23-42.

Bell, R. 1991. Translation and Translating:theory and practice. Longman. Harlow.

Biguenet, J. and Schulter, R. (eds) 1989. The Craft of Translation. University of Chicago. Chicago.

Bly, R. 1984. "The eight stages of translation" in Frawley, W. (ed.) 1984, 67-89.

Brower, R.A. 1966. On Translation. Oxford University Press. Oxford.

Brown and Yule, 1983. Discourse Analysis, Cambridge University Press. Cambridge.

Brown, C. 1973. Mandelstam, Cambridge University Press. Cambridge.

Catford, J.C. 1965. A Linguistic Theory of Translation. Oxford University Press. Oxford.

Chukovsky, K. The Art of Translation: a High Art. Translated and edited by L.G.Leighton. University of Tennessee Press. 1984.

Delisle Jean, 1988 (1980), Translation:an interpretive approach, translated by P. Logan and M. Creery, University of Ottawa Press, Canada.

Fillmore, C. 1977. "Scenes and Frames Semantics", in Dirven and Radden, (eds) Fillmore's Case Grammar: a reader, Julian Groos Verlag, Heidelberg.

Frawley, W. (ed.) 1984. Translation: Literan', Linguistic and Philosophical Perspectives. University of Delaware, Newark, DE.

Greene, James, 1980.Osip Mandelstam: Poems, Granada Publishing.

Halliday, M. 1985. An Introduction to Functional Grammar.London. Harlow.

Holmes. J.S. (ed.) 1970. The Nature of Translation Mouton, The Hague.

Jones, Francis, 1989, "On Aboriginal Sufferance: a process model of poetic translating", Target 1:2. 183-199, John Benjamin B.V. Amsterdam.

Kuic R. 1970. "Translating English Romantic Poetry" in Homes, J.S. (ed.) 1970, 182-191.

Lefevere, A. 1975. Translating Poetry: seven strategies and a blueprint van Gorcum. Assen.

McDuff, D. 1973. Selected Poems: Osip Mandel'stam. Rivers Press Ltd. Cambridge.

Nida, E. 1964. Towards a Science of Translating. Brill. Leyden.

Nida, E. 1966. "Principles of translation as exemplified by Bible translating" in Brower, R.A. (ed.) 1966. 11-31.

Nida, E.A. and Taber, C. 1974. The Theory and Practice of Translation. Brill. Leyden.

Sanford A.J and Garrod S.C. 1981. Understanding Written Language Wiley. Chichester.

Snell-Hornby, M. 1988. Translation Studies: an integrated approach. John Benjamin. Amsterdam.

Raffel, B. 1988. The An of Translating Poetry, Pennsylvania State U.P.

Tracy, R.(translator and ed.) 1981. Osip Mandelstam's Stone. Princeton University Press. Princeton.

Weaver, W. 1989. "The process of translation" in Biguenet,J. and Schulter, R. (eds) 1989, $117-24$.

Wilss, W. 1980. Semiotik und Übersetzen. Narr. Tübingen.

Wilss, W. 1982. The Science of Translation. Narr. Tübingen. 